\title{
Treatment of Pediatric Acute Lymphoblastic Leukemia and Recent Advances
}

\author{
Tai-Tsung Chang and Pei-Chin Lin \\ Kaohsiung Medical University Hospital, Kaohsiung Medical University
}

Taiwan

\section{Introduction}

Pediatric acute lymphoblastic leukemia (ALL) is the most prevalent cancer in children. Today in developed countries around $80 \%$ of children with ALL can achieve 10 year survival. This great improvement in treatment outcomes for pediatric ALL is due to several important advances which have taken place since the 1960s, including intensive induction/consolidation chemotherapy regimens, risk-adapted therapy, central nervous system prophylaxis, aggressive supportive care (especially prophylaxis and treatment for infections) and minimal residual disease detection. Rapid progress in molecular biology has helped to select patients with specific poor prognostic genetic factors and sensitive monitoring of minimal residual disease has also contributed significantly to the management of pediatric ALL. However, patients with extremely poor prognostic factors or delayed response to chemotherapy still experience disease relapse. Hematopoietic stem cell transplantation (HSCT), mainly using allogenic stem cells (bone marrow, peripheral blood or umbilical cord blood stem cells), has been proven to be an effective alternative and to ensure long-term survival for patients with relapsed ALL or with extremely poor prognostic factors. However, there are complications such as severe infections and chronic graftversus-host disease (GVHD) that may be occurred. Recent advances in the development of new formulations of existing drugs, targeted therapy and immunotherapy provide new options in treatment of patients with refractory disease and promise to further improve of the cure rates of pediatric ALL.

\section{Characteristics of pediatric acute lymphoblastic leukemia}

Leukemia is the most common malignancy in the pediatric population, comprising $30 \%$ of malignant tumors in children (Chiang et al., 2010; Young and Miller, 1975). The most prevalent subtypes of pediatric leukemia are acute lymphoblastic leukemia (75 80\%) and acute myelogenous leukemia (15 17\%)(Feltbower et al., 2009).

Common presenting symptoms of pediatric ALL include fever, pallor, hepatosplenomegaly, lymph node swelling and hemorrhage. Bone pain or arthralgia is sometimes reported. The diagnosis of pediatric ALL is based on examination of cell morphology, cytochemistry and immunochemical analysis of bone marrow aspirates. Pediatric ALL can be classified according to different characteristics: L1, L2 or L3 by morphology, and B-cell, T-cell, coexpression of myeloid antigens or mixed type by immunophenotyping. Risk-adapted 
therapy is the main strategy for pediatric ALL treatment and has achieved a 5-year eventfree survival rate of approximately $80 \%$ in recent years.

\section{Chemotherapy}

\subsection{Basic treatment principles}

Treatment for pediatric ALL comprises two major components: multi-drug combination chemotherapy and intrathecal (IT) chemotherapy for central nervous system (CNS) prophylaxis. Modern protocols have a number of design elements in common including a remission induction phase, a consolidation/intensification phase, and a CNS treatment and continuation (maintenance) phase, with or without delayed intensification (Provan et al., 2009). Multi-drug combination chemotherapy has been the mainstay of ALL management since the late 1960s and a major survival improvement was achieved when 8-week, 8-drug induction/consolidation regimens followed by maintenance therapy were introduced in the 1970s. CNS prophylaxis therapy with IT chemotherapy alone or with cranial radiation was added to the treatment regimen after the induction phase and markedly reduced CNS involvement in leukemia from around $80 \%$ to $4 \sim 6 \%$ (Evans et al., 1970; Moghrabi et al., 2007; Pui, C.H. et al., 2009). Following consolidation treatment, maintenance chemotherapy is initiated and continued for 2 3 years.

\subsection{Evolution of regimens}

During the late 1960s and early 1970s, patients with pediatric ALL were treated with a threedrug regimen (vincristine, prednisolone and asparaginase) to induce remission, CNS prophylaxis therapy with weekly IT methotrexate (MTX) and cranial radiation was performed during the intensification phase followed by continuation treatment consisting of daily oral mercaptopurine, weekly oral MTX and monthly pulses of prednisolone and vincristine (Schrappe et al., 2010). Later, an early multiple agent induction/consolidation regimen was developed by Dr Riehm (Riehm et al., 1977). This comprised 8-drug induction chemotherapy for 9 weeks (prednisolone, daunorubicin, vincristine, asparaginase, methotrexate, mercaptopurine, cyclophosphamide and cytarabine) and 4 cycles of high-dose methotrexate (HDMTX) with daily oral mercaptopurine for 8 weeks. This improved the cure rate to over $50 \%$. The high remission rate was thought to be related to the intensified remission induction phase. The requirement for precise and robust supportive care in specialized hospitals undertaken by experienced medical staff was emphasized in order to control treatment-related complications (Riehm et al., 1977; Schrappe et al., 2010). This approach remains at the core of modern pediatric ALL regimens.

Risk-adapted therapy stratified by age and initial white blood cell count was demonstrated to increase the remission rate in poor risk groups and to decrease acute and chronic toxicities in good risk groups (Henze et al., 1981). The system of risk classification based on age and white blood cell count was extended by addition of other important prognostic factors for pediatric ALL (Table 1). The application of risk-adapted therapy in clinical trials has resulted in a steady improvement in the outcome of pediatric ALL, with a current overall survival rate of around $80 \%$ in developed countries (Jeha and Pui, 2009). The significance of early response to induction treatment, as measured by reduction in peripheral blood blast cells, was proposed in 1987 and used as an indicator to divide patients into different risk groups (Riehm et al., 1987). Since then, many more prognostic 
factors have been identified and integrated into risk-classification systems. With the advances in genome-wide screening techniques, pharmacogenomic studies, and development of molecular therapeutics an era of more refined personalized therapy is anticipated (Pui, C.H., 2010).

\begin{tabular}{|l|l|l|l|l|l|l|}
\hline $\begin{array}{l}\text { Risk } \\
\text { group }\end{array}$ & $\begin{array}{l}\text { Age } \\
(\mathrm{y})\end{array}$ & $\begin{array}{l}\text { Leukocyte } \\
\text { count }(/ \mathrm{ul})\end{array}$ & Immunophenotype & Chromosome & Genotype & $\begin{array}{l}\text { Early response } \\
\text { to } \\
\text { chemotherapy\# }\end{array}$ \\
\hline Low & $1-9$ & $<50,000$ & Precursor B-cell & Hyperdiploidy* & TEL-AML1 & Good \\
\hline High & $\begin{array}{l}<1 \text { or } \\
\geqq 10\end{array}$ & $>50,000$ & T-cell & Hypodiploidy* & $\begin{array}{l}\text { MLL-AF4 } \\
B C R-A B L\end{array}$ & Poor \\
\hline
\end{tabular}

*hyperdiploidy: >50 chromosome; hypodiploidy: <44 chromosome

\#defined as MRD at the end of induction chemotherapy (good response: MRD $<0.01 \%$; poor response: $\mathrm{MRD} \geqq 1 \%)$

Table 1. Prognostic factors used for risk classification in pediatric ALL (adapted from (Pui, C.H., 2010) with permission)

National and international treatment groups have been established worldwide with the objective of improving the management of childhood ALL. The long-term results of recently completed clinical trials are listed in Table 2 (Conter et al., 2010; Gaynon et al., 2010; Liang et al., 2010; Mitchell et al., 2010; Moricke et al., 2010; Pui, C.H. et al., 2010). In Taiwan, the Taiwan Pediatric Oncology Group was formed in 1988 and marked progress in ALL treatment has been achieved with overall survival increasing from 59\% during 1988 1995 to $82 \%$ during 2003 2009.

\begin{tabular}{|l|l|l|l|l|l|}
\hline $\begin{array}{l}\text { Study } \\
\text { group }\end{array}$ & Trial & Year & Case number & $\begin{array}{l}10 \text {-year EFS } \\
(\%)\end{array}$ & $\begin{array}{l}10 \text {-year OS } \\
(\%)\end{array}$ \\
\hline CCG & CCG-1900 & $1996-2002$ & 4464 & 72.6 & 82.1 \\
\hline AIEOP & $\begin{array}{l}\text { AIEOP-ALL } \\
95\end{array}$ & $1995-2000$ & 1743 & 71.7 & 82.4 \\
\hline BFM & ALL-BFM 95 & $1995-2000$ & 2169 & 78 & 85 \\
\hline SJCRH & Total 13B & $1994-1998$ & 247 & $80.1^{*}$ & $85.7^{*}$ \\
\hline SJCRH & Total 14 & $1998-1999$ & 53 & 79.2 & 77.4 \\
\hline SJCRH & Total 15 & $2000-2007$ & 498 & $85.6^{*}$ & $93.5^{*}$ \\
\hline $\begin{array}{l}\text { UK- } \\
\text { WPCL }\end{array}$ & UKALL 97 & $1997-2002$ & 1948 & 74 & 83 \\
\hline TPOG & TPOG-2002 & $2002-2007$ & 788 & $77.4^{*}$ & $83.5^{*}$ \\
\hline
\end{tabular}

CCG: Children's Cancer Group; AIEOP: Associazione Italiana di ematologia ed Oncologia Pediatrica; BFM: Berlin-Frankfurt-Munster ALL Study Group; SJCRH: St Jude Children's Research Hospital; UKWPCL: UK Medical Research Council Working Party on Childhood Leukemia; TPOG: Taiwan Pediatric Oncology group; EFS: event-free survival; OS: overall survival ; *5-year EFS and OS

Table 2. Treatment outcomes for selected pediatric ALL study groups

\subsection{Central nervous system treatment}

Early in the 1960s central nervous system(CNS) treatment was applied to the "total" therapy for pediatric ALL since it was found that better control of systemic leukemia was 
accompanied by increased frequency of CNS involvement (Aur, R.J. and Pinkel, 1973; Simone, J.V., 1973). Radiation therapy of the CNS and IT MTX administration were the two main strategies for preventing CNS disease (Glidewell and Holland, 1973; Kim et al., 1972; Rosner and Grunwald, 1973; Simone, J. and Pinkel, 1973). Dosage and treatment modalities of CNS radiation were studied in an attempt to reduce neurotoxicities while maintaining effectiveness (Simpson et al., 1973). The St. Jude leukemia group compared cranial radiation with IT MTX and craniospinal irradiation in clinical trials and suggested that combined cranial radiation and IT MTX treatment was as effective as craniospinal irradiation with fewer toxicities (leukopenia and interruption of treatment)(Aur, R.J.A. et al., 1973). Since then, combined cranial irradiation and IT MTX have become the standard treatment for preventing CNS disease. However, further studies revealed that survivors of pediatric ALL who received high doses of cranial irradiation (over $25 \mathrm{~Gy}$ ) or who were treated at a young age (younger than 2 years) suffered from significant long-term sequelae, such as defective cognitive function and secondary malignancy (Moe and Holen, 2000; Spiegler et al., 2006). Therefore, some study groups suggested that the dose of radiation be decreased to less than 18 Gy (Henze et al., 1983) or that the extended IT MTX treatment be used as a replacement for cranial irradiation in low-risk patients (Conter et al., 1995). However, some treatment groups preferred to continue to employ cranial irradiation because of the poor prognosis with CNS leukemia (Gelber et al., 1993). After a lengthy debate regarding the role of cranial irradiation in pediatric ALL treatment, $\mathrm{Pui} \mathrm{CH}$ et al. published their study results in this issue and suggested that 'with effective risk-adjusted chemotherapy, prophylactic cranial irradiation can be safely omitted from the treatment of childhood ALL'(Pui, C.H. et al., 2009).

\section{Minimal residual disease}

Complete remission of ALL has been defined as blastic cells less than $5 \%$ of nucleated cells on bone marrow smear. Before the introduction of molecular methods or multicolor flow cytometry techniques, the percentage of blastic cells was measured by morphology, with a sensitivity of $1 \%$. During the last twenty years, rapid progress in molecular biology has greatly improved the sensitivity of residual blastic cell detection, especially in the range $1 \%$ to $0.01 \%$, which is designated minimal residual disease (MRD) (Campana and Pui, 1995; Neale et al., 1994). A new definition of remission was then established on the basis of immunologic or molecular response. A better clinical outcome is predicted in patients who achieve 'immunologic' or 'molecular' remission (ie leukemic involvement of $<0.01 \%$ of nucleated bone marrow cells after initial intensive chemotherapy) compared with patients whose remission is defined solely by morphologic criteria (Coustan-Smith et al., 2000; Pui, C.H. and Campana, 2000). Among the various methods using immunologic or molecular characteristics of blastic cells as markers, the most promising are flow cytometric detection of aberrant immunophenotypes, and polymerase chain reaction analysis of clonal antigenreceptor gene rearrangements or leukemia-specific fusion genes (Campana and Pui, 1995; Coustan-Smith et al., 1998; Ludwig et al., 1990; van Dongen et al., 1999). Taken together, almost all patients with pediatric ALL can be monitored for MRD during the course of treatment (Campana et al., 2001; Chen et al., 2001; Neale et al., 2004; Pui, C.H. and Campana, 2000). Recent studies indicated that monitoring of MRD constituted an essential prognostic marker, and that detection of MRD, particularly at the end of induction and after treatment 
completion, was significantly predictive for patient outcome (Katsibardi et al., 2010; Stow et al., 2010).

\section{The role of hemopoietic stem cell transplantation in pediatric acute lymphoblastic leukemia}

Hemopoietic stem cell transplantation was introduced for children with ALL in the 1970s. Along with the significant improvements in clinical outcome observed in patients receiving chemotherapy, HSCT became the treatment choice for relapsed cases and patients with poor prognostic factors (Gratwohl et al., 1990; Makipernaa et al., 1995; Uderzo et al., 1995). In early studies, 40 to $50 \%$ of relapsed patients achieved long remissions and were potentially cured by marrow transplantation. However, the effectiveness of the approach was diminished by the problems of acute and chronic GVHD, infection, and relapse(Johnson, 1990; Moussalem et al., 1995; Pinkel, 1994; Wingard et al., 1990). Currently, HSCT is only considered in patients with extremely poor prognostic factors (for example, Philadelphia chromosome positive $\left[\mathrm{PH}^{+}\right]$ALL with poor response to induction therapy), with delayed response to chemotherapy (induction failure, $\mathrm{MRD}>1 \%$ on the end of remission date or MRD $>0.01 \%$ prior to reinduction of chemotherapy) and in patients who experience early relapse (Arico et al., 2010; Burke et al., 2009; Davies and Mehta, 2010; Pulsipher et al., 2011).

\section{Recent advances in therapy and research in pediatric ALL}

Philadelphia chromosome-positive ALL has been found to be associated with a poor response to conventional chemotherapy and a high relapse rate, especially in patients older than 10 years (Arico et al., 2010). HSCT has been employed in patients with $\mathrm{PH}^{+}$ALL in an attempt to improve long-term outcomes. In the early 2000s, BCR-ABL targeted strategies started to be incorporated into the treatment for $\mathrm{PH}^{+}$ALL. Imatinib, a first generation tyrosine kinase inhibitor, showed its efficacy in improving the treatment outcome in $\mathrm{PH}^{+}$ALL with or without HSCT (Alvarado et al., 2007; Carpenter et al., 2007; Champagne et al., 2004; Fuster et al., 2007; Jones, L.K. and Saha, 2005). Given the marked improvement in treatment results achieved with combinations of a tyrosine kinase inhibitor (imatinib) and intensive chemotherapy, transplantation is not recommended for the first remission of children with PH+ ALL, unless the early response to treatment was poor (Barr, 2010; Gruber et al., 2009; Koo, 2011; Liu et al., 2009; Milone and Enrico, 2009; Ottmann and Pfeifer, 2009; Schultz et al., 2009). Second generation tyrosine kinase inhibitors were developed because imatinib may induce specific resistance mainly due to ABL1 mutations. Dasatinib, a multi tyrosine kinase inhibitor targeted to BCR-ABL, SRC, C-KIT, PDGFR and ephrin A receptor kinase, and nilotinib, another BCR-ABL targeted agent similar to imatinib but with a higher affinity, are two novel agents with the potential to address PH+ALL resistance to imatinib (Alvarado et al., 2007; Aplenc et al., 2011; Kawaguchi et al., 2005; Kolb et al., 2008; Linger et al., 2009; Piccaluga et al., 2007; Porkka et al., 2008).

Mixed lineage leukemia (MLL) rearrangements occur in $80 \%$ of infants and $5 \%$ of older children with ALL. MLL-rearranged ALL patients have poor treatment outcomes with conventional chemotherapy. FLT3 (FMS-like tyrosine kinase receptor-3) is one of the unique gene expression profiles in MLL-rearranged ALL. Eighteen percent of MLL-rearranged ALL harbored activating mutations of FLT3 with high expression levels (Armstrong et al., 2003; Brown et al., 2005). In vitro studies have demonstrated that FLT3 inhibitor, CEP-701, 
effectively suppresses FLT3 driven leukemic cell survival (Brown et al., 2006; Brown et al., 2005).

Monoclonal antibodies, including rituximab (anti-CD20), epratuzumab (anti-CD22), inotuzumab (anti-CD22), recombinant immunotoxins and bispecific antibodies (blinatumomab) and radioimmunotherapy have already been incorporated into clinical trials or are undergoing investigation. (Attias and Weitzman, 2008; Christiansen and Rajasekaran, 2004; Dworzak et al., 2008; Oriuchi et al., 2005; Reichert and Valge- Archer, 2007; Topp et al., 2011)

The application of emerging DNA and RNA techniques, SNP arrays, DNA methylation arrays and genome-wide association studies has led to the discovery of further genetic and epigenetic alterations. IKZF1, JAK mutations, and CDKN2A/B are among several examples which have been shown to be related to leukemogenesis and drug resistance (Davidsson et al., 2009; Yang et al., 2009; Yu et al., 2011). MicroRNAs alterations and dysregulation of DNA methylation have also been found in children with ALL and are being assessed as new targets for treatment (Bachmann et al., 2010; Davidsson et al., 2009; Herman et al., 1996; Schotte et al., 2011). In the near future, more individualized treatment strategies will be established based on detailed genetic and epigenetic characteristics, response to early treatment and MRD monitoring Such strategies will require precise supportive care.

\section{Supportive care}

\subsection{Tumor lysis syndrome}

Tumor lysis syndrome (TLS) is a well-recognized complication of leukemia and lymphoma, especially in patients with B-cell or T-cell neoplasms and a large tumor burden (Alperin and Levin, 1964; Cohen et al., 1980; Jones, D.P. et al., 1990; Kedar et al., 1995; Kuhbock et al., 1968; Rieselbach et al., 1964). TLS may occur spontaneously or during the early phase of treatment and can lead to severe metabolic disturbances (hyperuricemia, hyperphosphatemia, hyperkalemia, and hypocalcemia) (Jones, D.P. et al., 1995). TLSassociated hyperuricemia may cause acute renal failure because of the rapid and dramatic increase of uricemia and renal burden of uric acid urate. Without appropriate management, precipitation of uric acid crystals can obstruct the tubules and collecting ducts, resulting in tubular necrosis and renal failure (Renyi et al., 2007). Allopurinol, which is an inhibitor of the enzyme xanthine oxidase, combined with hydration, osmotic diuretics and urinary alkalization has been the standard treatment for TLS since the late 1960s and remains an important part of leukemia treatment (Aviles, 1995; DeConti and Calabresi, 1966; Holland and Holland, 1968; Jones, D.P. et al., 1995; Rundles, 1966; Watts, 1966). Through blocking uric acid formation, allopurinol can effectively lower the serum uric acid level, but it increases the renal load of hypoxanthine and xanthine (both are uric acid precursors) (Andreoli et al., 1986; DeConti and Calabresi, 1966). Allopurinol treatment has been associated with xanthine nephropathy and calculi because xanthine is actually less soluble than uric acid in urine (Band et al., 1970; Wyngaarden, 1970). Moreover, allopurinol may interact with chemotherapy agents and affect drug metabolite concentrations (Rundles, 1966).

Urate oxidase, an endogenous enzyme in most mammals but not in humans, can act as a catalyst in the oxidation of uric acid to allantoin. Because allantoin is five to ten-fold more soluble than uric acid, urate oxidase can effectively decrease uric acid levels in patients with TLS (Brogard et al., 1972). Recombinant urate oxidase was introduced in France in 1975. During the 1980s and 1990s, non-recombinant urate oxidase (Uricozyme; Sanofi-Synthelabo, 
Inc, Paris), purified from cultures of Aspergillus flavus, was used in the treatment of TLS in ALL patients (Masera et al., 1982). Although it improved the elimination of uric acid, however, this agent was found to be associated with allergic reactions (rashes, bronchospasm, urticaria and angioedema) in about $5 \%$ of patients, even in those without a history of allergy (Patte et al., 2001; Pui, C.H. et al., 1997). A new urate oxidase (rasburicase) was developed by use of a recombinant DNA technique in 1996 (Cammalleri and Malaguarnera, 2007). This approach allowed more rapid production of greater quantities of urate oxidase. Rasburicase is purer than non-recombinant urate oxidase, has greater activity and lower allergic reaction rates. Studies of the use of rasburicase in patients with ALL, have shown it to be a safe and effective alternative to allopurinol for the prevention and treatment of hyperuricemia (Cammalleri and Malaguarnera, 2007; Cheson and Dutcher, 2005; Lee et al., 2003; McNutt et al., 2006; Patte et al., 2001; Pui, C.H., 2001; Sood et al., 2006; Wang et al., 2006). The toxicity of rasburicase is negligible, although the presence of anti-rasburicase antibodies has been reported in some patients (Pui, C.-H. et al., 2001).

\subsection{Infections}

Neutropenia is usually found when ALL is newly diagnosed or during chemotherapy, especially induction therapy. Children with ALL and disease-induced or treatment-related neutropenia, (usually defined as absolute neutrophil count less than 500 per $\mathrm{mm}^{3}$ ) are more prone to severe bacterial, fungal and viral infections (Freifeld et al., 2011). More febrile neutropenia episodes occur during induction of remission than during remission in children with ALL. The risk of severe infection is high with severe neutropenia (less than 200 per $\mathrm{mm}^{3}$ )(Jones, G.R. et al., 1996; Peng et al., 1981). Both the degree and duration of neutropenia affect the risk of infection. For the purpose of managing febrile neutropenia, patients have been categorized into different risk groups. Rackoff et al. classified patients with febrile neutropenia into three risk groups based on the absolute monocyte count and temperature at the time of admission. They found that the odds ratio of bacteremia for the high-risk versus the intermediate-risk group is 4.4 (no bacteremia episodes were found in the low-risk group)(Rackoff et al., 1996). The Infectious Disease Society of America (IDSA) started categorizing patients with febrile neutropenia in 2002 and the updated recommendation published in 2010 divided these patients into high-risk or low-risk groups according to the presenting symptoms and signs, neutrophil counts, underlying cancer, type of therapy, the anticipated length of neutropenia and medical comorbidities. The high-risk group was defined when any of the following criteria applied : profound neutropenia anticipated for longer than 7 days, evidence of hepatic or renal insufficiency, comorbidities with unstable vital signs, severe mucositis, gastrointestinal symptoms, neurological symptoms, catheterrelated infections, new pulmonary infiltration or hypoxia (Freifeld et al., 2011). It was suggested that high-risk patients be admitted at once and that antibiotics should be administered on an empirical basis as soon as possible. Worldwide, the etiology of infections is now predominantly due to Gram-positive bacterial pathogens. In a study conducted in 1981, Gram-positive and Gram-negative bacteria were equally represented (Peng et al., 1981). In another study, Gram-negative bacteria accounted for the great majority of the etiologic agents (Escherichia coli, Klebsiella spp. and Pseudomonas aeruginosa were the three most common pathogens) (Bodey et al., 1978). Recent studies have showed that Gram-positive bacteria account for more than fifty percent of bacterial episodes with coagulase-negative staphylococci, viridans streptococci and Staphylococcus aureus being the most common pathogens (Hakim et al., 2009). 
Systemic (invasive) fungal infections are another common infection in patients with febrile neutropenia. ALL was the second most common underlying disease associated with proven invasive fungal infections after acute myelogenous leukemia in children treated for cancers (Mor et al., 2011). In earlier studies, systemic fungal infections occurred in around $20 \%$ of cases of pediatric acute leukemia during induction chemotherapy and the duration of neutropenia was a significant risk factor (Wiley et al., 1990). In the late 1990s, when antifungal prophylaxis and early initiation of empirical antifungal therapy were introduced, the rate of invasive fungal infections decreased, although the rate of fungal colonization in children receiving remission induction therapy for acute leukemia was still high (Gozdasoglu et al., 1999). In a study conducted in 2007, the occurrence of invasive fungal infections was monitored after renovation of the ventilation system on a pediatric hematology/oncology unit and initiation of routine azole antifungal prophylaxis. The incidence of proven invasive fungal infection was 3.2\% (1/31) in the allogenic stem cell transplant group, $0 / 26$ in autologous stem cell transplant group and $1.6 \%(1 / 60)$ in the induction therapy group (Hovi et al., 2007). In 2010, IDSA guidelines proposed antifungal prophylaxis administration in high-risk groups, and empiric antifungal therapy or preemptive therapy in patients with febrile neutropenia 4-7 days after broad-spectrum antibiotics treatment (Freifeld et al., 2011). However, a shift of fungal pathogens from Candida sp. towards mold infections was observed along with the increasing use of antifungal prophylaxis. In a recent study which enrolled 1047 children with different malignancies, $20 \%$ of the proven invasive fungal infections had candidemia and $80 \%$ had mold infections. Non-albicans candida accounted for $60 \%$ of all candidemia and $55 \%$ of mold infections were non-Aspergillus (Mor et al., 2011). Although the incidence of and mortality due to invasive fungal infections were both lower than previously reported, the epidemiologic spectrum of fungus isolates has broadened and this should be considered in the selection of antifungal agents for prophylaxis or empirical treatment.

Granulocyte-colony stimulation factor (G-CSF) or granulocyte-monocyte colony stimulating factor (GM-CSF) have the potential benefits of reducing the duration of neutropenia and, in turn, the risk of infection. A meta-analysis of 16 randomized controlled trials concluded that prophylactic use of G-CSF or GM-CSF was associated with a $20 \%$ reduction in febrile neutropenia and a two-day decrease in duration of hospitalizations (Sung et al., 2004). IDSA 2010 guidelines recommend prophylactic use of G-CSF or GM-CSF for patients in whom the predicted risk of fever and neutropenia is over 20\% (Freifeld et al., 2011).

\section{Conclusion}

Pediatric ALL is the most common malignancy in children. The cure rates of pediatric ALL have improved greatly through use of risk-adapted therapy and aggressive supportive care. Advances in molecular biology and high-throughput technology will allow further investigation of the mechanisms of leukemogenesis and disease relapse and will, in turn, lead to more sophisticated treatments in the future.

\section{Acknowledgements}

The authors thank the members of Taiwan Pediatric Oncology Group (TPOG) for their distinguished work and all of our colleagues at the Division of Hematology/Oncology, Department of Pediatrics, Kaohsiung Medical University Hospital. 


\section{References}

Alperin, J. B. and Levin, W. C. (1964). "Extreme Hyperuricemia Associated with Prednisone Therapy for Acute Lymphoblastic Leukemia." Tex Med 60: 1001-4.

Alvarado, Y., et al. (2007). "Emerging therapeutic options for Philadelphia-positive acute lymphocytic leukemia." Expert Opin Emerg Drugs 12(1): 165-79.

Andreoli, S. P., et al. (1986). "Purine excretion during tumor lysis in children with acute lymphocytic leukemia receiving allopurinol: relationship to acute renal failure." J Pediatr 109(2): 292-8.

Aplenc, R., et al. (2011). "Pediatric phase I trial and pharmacokinetic study of dasatinib: a report from the children's oncology group phase I consortium." J Clin Oncol 29(7): 839-44.

Arico, M., et al. (2010). "Clinical outcome of children with newly diagnosed Philadelphia chromosome-positive acute lymphoblastic leukemia treated between 1995 and 2005." J Clin Oncol 28(31): 4755-61.

Armstrong, S. A., et al. (2003). "Inhibition of FLT3 in MLL. Validation of a therapeutic target identified by gene expression based classification." Cancer Cell 3(2): 173-83.

Attias, D. and Weitzman, S. (2008). "The efficacy of rituximab in high-grade pediatric B-cell lymphoma/leukemia: a review of available evidence." Curr Opin Pediatr 20(1): 1722.

Aur, R. J. and Pinkel, D. (1973). "Total therapy of acute lymphocytic leukemia." Prog Clin Cancer 5: 155-70.

Aur, R. J. A., et al. (1973). "Comparison of Two Methods of Preventing Central Nervous System Leukemia." Blood 42(3): 349-357.

Aviles, A. (1995). "Acute tumor lysis syndrome and alkali therapy." Am J Med 98(4): 417-8.

Bachmann, P. S., et al. (2010). "Epigenetic silencing of BIM in glucocorticoid poor-responsive pediatric acute lymphoblastic leukemia, and its reversal by histone deacetylase inhibition." Blood 116(16): 3013-22.

Band, P. R., et al. (1970). "Xanthine nephropathy in a patient with lymphosarcoma treated with allopurinol." N Engl J Med 283(7): 354-7.

Barr, R. D. (2010). "Imatinib mesylate in children and adolescents with cancer." Pediatr Blood Cancer 55(1): 18-25.

Bodey, G. P., et al. (1978). "Fever and infection in leukemic patients: a study of 494 consecutive patients." Cancer 41(4): 1610-22.

Brogard, J. M., et al. (1972). "Enzymatic uricolysis: a study of the effect of a fungal urateoxydase." Rev Eur Etud Clin Biol 17(9): 890-5.

Brown, P., et al. (2006). "Combinations of the FLT3 inhibitor CEP-701 and chemotherapy synergistically kill infant and childhood MLL-rearranged ALL cells in a sequencedependent manner." Leukemia 20(8): 1368-76.

Brown, P., et al. (2005). "FLT3 inhibition selectively kills childhood acute lymphoblastic leukemia cells with high levels of FLT3 expression." Blood 105(2): 812-20.

Burke, M. J., et al. (2009). "Allogeneic hematopoietic cell transplantation (allogeneic HCT) for treatment of pediatric Philadelphia chromosome-positive acute lymphoblastic leukemia (ALL)." Pediatr Blood Cancer 53(7): 1289-94. 
Cammalleri, L. and Malaguarnera, M. (2007). "Rasburicase represents a new tool for hyperuricemia in tumor lysis syndrome and in gout." Int J Med Sci 4(2): 83-93.

Campana, D., et al. (2001). "Detection of minimal residual disease in acute lymphoblastic leukemia: the St Jude experience." Leukemia 15(2): 278-9.

Campana, D. and Pui, C. H. (1995). "Detection of minimal residual disease in acute leukemia: methodologic advances and clinical significance." Blood 85(6): 1416-34.

Carpenter, P. A., et al. (2007). "Prophylactic administration of imatinib after hematopoietic cell transplantation for high-risk Philadelphia chromosome-positive leukemia." Blood 109(7): 2791-3.

Champagne, M. A., et al. (2004). "Imatinib mesylate (STI571) for treatment of children with Philadelphia chromosome-positive leukemia: results from a Children's Oncology Group phase 1 study." Blood 104(9): 2655-60.

Chen, X., et al. (2001). "Quantification of minimal residual disease in T-lineage acute lymphoblastic leukemia with the TAL-1 deletion using a standardized real-time PCR assay." Leukemia 15(1): 166-70.

Cheson, B. D. and Dutcher, B. S. (2005). "Managing malignancy-associated hyperuricemia with rasburicase." J Support Oncol 3(2): 117-24.

Chiang, C.-J., et al. (2010). "Cancer Trends in Taiwan." Japanese Journal of Clinical Oncology 40(10): 897-904.

Christiansen, J. and Rajasekaran, A. K. (2004). "Biological impediments to monoclonal antibody-based cancer immunotherapy." Mol Cancer Ther 3(11): 1493-501.

Cohen, L. F., et al. (1980). "Acute tumor lysis syndrome. A review of 37 patients with Burkitt's lymphoma." Am J Med 68(4): 486-91.

Conter, V., et al. (2010). "Long-term results of the Italian Association of Pediatric Hematology and Oncology (AIEOP) Studies 82, 87, 88, 91 and 95 for childhood acute lymphoblastic leukemia." Leukemia 24(2): 255-64.

Conter, V., et al. (1995). "Extended intrathecal methotrexate may replace cranial irradiation for prevention of CNS relapse in children with intermediate-risk acute lymphoblastic leukemia treated with Berlin-Frankfurt-Munster-based intensive chemotherapy. The Associazione Italiana di Ematologia ed Oncologia Pediatrica." J Clin Oncol 13(10): 2497-502.

Coustan-Smith, E., et al. (1998). "Immunological detection of minimal residual disease in children with acute lymphoblastic leukaemia." Lancet 351(9102): 550-4.

Coustan-Smith, E., et al. (2000). "Clinical importance of minimal residual disease in childhood acute lymphoblastic leukemia." Blood 96(8): 2691-6.

Davidsson, J., et al. (2009). "The DNA methylome of pediatric acute lymphoblastic leukemia." Hum Mol Genet 18(21): 4054-65.

Davies, S. M. and Mehta, P. A. (2010). "Pediatric acute lymphoblastic leukemia: is there still a role for transplant?" Hematology Am Soc Hematol Educ Program 2010: 363-7.

DeConti, R. C. and Calabresi, P. (1966). "Use of allopurinol for prevention and control of hyperuricemia in patients with neoplastic disease." N Engl J Med 274(9): 481-6.

Dworzak, M. N., et al. (2008). "CD20 up-regulation in pediatric B-cell precursor acute lymphoblastic leukemia during induction treatment: setting the stage for anti-CD20 directed immunotherapy." Blood 112(10): 3982-8. 
Evans, A. E., et al. (1970). "The increasing incidence of central nervous system leukemia in children. (Children's Cancer Study Group A)." Cancer 26(2): 404-9.

Feltbower, R. G., et al. (2009). "Epidemiology of leukaemia and lymphoma in children and young adults from the north of England, 1990-2002." European Journal of Cancer 45(3): 420-427.

Freifeld, A. G., et al. (2011). "Clinical practice guideline for the use of antimicrobial agents in neutropenic patients with cancer: 2010 update by the infectious diseases society of america." Clin Infect Dis 52(4): e56-93.

Fuster, J. L., et al. (2007). "Imatinib mesylate in combination with chemotherapy in four children with de novo and advanced stage Philadelphia chromosome-positive acute lymphoblastic leukemia." Haematologica 92(12): 1723-4.

Gaynon, P. S., et al. (2010). "Long-term results of the children's cancer group studies for childhood acute lymphoblastic leukemia 1983-2002: a Children's Oncology Group Report." Leukemia 24(2): 285-97.

Gelber, R. D., et al. (1993). "Central nervous system treatment in childhood acute lymphoblastic leukemia. Long-term follow-up of patients diagnosed between 1973 and 1985." Cancer 72(1): 261-70.

Glidewell, O. J. and Holland, J. F. (1973). "Clinical trials of the acute leukemia group B in acute lymphocytic leukemia of childhood." Bibl Haematol 39: 1053-67.

Gozdasoglu, S., et al. (1999). "Fungal colonization and infection in children with acute leukemia and lymphoma during induction therapy." Med Pediatr Oncol 32(5): 3448.

Gratwohl, A., et al. (1990). "Allogeneic bone marrow transplantation for leukemia in Europe: regional differences. Report from the Leukemia Working party of the European Group for Bone Marrow Transplantation." Bone Marrow Transplant 5(3): 159-65.

Gruber, F., et al. (2009). "Impact of tyrosine kinase inhibitors on patient outcomes in Philadelphia chromosome-positive acute lymphoblastic leukaemia." Br J Haematol 145(5): 581-97.

Hakim, H., et al. (2009). "Etiology and clinical course of febrile neutropenia in children with cancer." J Pediatr Hematol Oncol 31(9): 623-9.

Henze, G., et al. (1983). "[Results of preventive management of the central nervous system in 275 children with acute lymphoblastic leukemia]." Klin Padiatr 195(3): 168-75.

Henze, G., et al. (1981). "Treatment strategy for different risk groups in childhood acute lymphoblastic leukemia: A Report From the BFM Study Group." Haematol Blood Transfus 26: 87-93.

Herman, J. G., et al. (1996). "Hypermethylation-associated inactivation indicates a tumor suppressor role for p15INK4B." Cancer Res 56(4): 722-7.

Holland, P. and Holland, N. H. (1968). "Prevention and management of acute hyperuricemia in childhood leukemia." J Pediatr 72(3): 358-66.

Hovi, L., et al. (2007). "Prevention and monitoring of invasive fungal infections in pediatric patients with cancer and hematologic disorders." Pediatr Blood Cancer 48(1): 28-34.

Jeha, S. and Pui, C. H. (2009). "Risk-adapted treatment of pediatric acute lymphoblastic leukemia." Hematol Oncol Clin North Am 23(5): 973-90, v. 
Johnson, F. L. (1990). "Role of bone marrow transplantation in childhood lymphoblastic leukemia." Hematol Oncol Clin North Am 4(5): 997-1008.

Jones, D. P., et al. (1995). "Tumor lysis syndrome: pathogenesis and management." Pediatr Nephrol 9(2): 206-12.

Jones, D. P., et al. (1990). "Renal dysfunction and hyperuricemia at presentation and relapse of acute lymphoblastic leukemia." Med Pediatr Oncol 18(4): 283-6.

Jones, G. R., et al. (1996). "Infection risk factors in febrile, neutropenic children and adolescents." Pediatr Hematol Oncol 13(3): 217-29.

Jones, L. K. and Saha, V. (2005). "Philadelphia positive acute lymphoblastic leukaemia of childhood." Br J Haematol 130(4): 489-500.

Katsibardi, K., et al. (2010). "Sequential monitoring of minimal residual disease in acute lymphoblastic leukemia: 7-year experience in a pediatric hematology/oncology unit." Leuk Lymphoma 51(5): 846-52.

Kawaguchi, H., et al. (2005). "In vitro drug resistance to imatinib and mutation of ABL gene in childhood Philadelphia chromosome-positive $(\mathrm{Ph}+)$ acute lymphoblastic leukemia." Leuk Lymphoma 46(2): 273-6.

Kedar, A., et al. (1995). "Clinical versus laboratory tumor lysis syndrome in children with acute leukemia." Pediatr Hematol Oncol 12(2): 129-34.

Kim, T., et al. (1972). "The role of central nervous system irradiation in children with acute lymphoblastic leukemia." Radiology 104(3): 635-41.

Kolb, E. A., et al. (2008). "Initial testing of dasatinib by the pediatric preclinical testing program." Pediatr Blood Cancer 50(6): 1198-206.

Koo, H. H. (2011). "Philadelphia chromosome-positive acute lymphoblastic leukemia in childhood." Korean J Pediatr 54(3): 106-10.

Kuhbock, J., et al. (1968). "[Hyperuricemia and kidney function in hemoblastoses]." Wildl Dis $49(10): 392-400$.

Lee, A. C., et al. (2003). "Treatment of impending tumor lysis with single-dose rasburicase." Ann Pharmacother 37(11): 1614-7.

Liang, D. C., et al. (2010). "Long-term results of Taiwan Pediatric Oncology Group studies 1997 and 2002 for childhood acute lymphoblastic leukemia." Leukemia 24(2): 397405.

Linger, R. M., et al. (2009). "Mer receptor tyrosine kinase is a novel therapeutic target in pediatric B-cell acute lymphoblastic leukemia." Blood 114(13): 2678-87.

Liu, Z., et al. (2009). "[Clinical characteristics and outcomes of 59 patients with acute lymphoblastic leukemia positive for BCR/ABL]." Nan Fang Yi Ke Da Xue Xue Bao 29(3): 512-5.

Ludwig, W. D., et al. (1990). "Possibilities and limitations of immunological marker analyses for the detection of minimal residual disease in childhood acute lymphoblastic leukemia." Onkologie 13(3): 166-74.

Makipernaa, A., et al. (1995). "Allogeneic bone marrow transplantation in children: single institution experience from 1974 to 1992." Acta Paediatr 84(6): 683-8.

Masera, G., et al. (1982). "Urate-oxidase prophylaxis of uric acid-induced renal damage in childhood leukemia." J Pediatr 100(1): 152-5. 
McNutt, D. M., et al. (2006). "Rasburicase for the management of tumor lysis syndrome in neonates." Ann Pharmacother 40(7-8): 1445-50.

Milone, J. H. and Enrico, A. (2009). "Treatment of Philadelphia chromosome-positive acute lymphoblastic leukemia." Leuk Lymphoma 50 Suppl 2: 9-15.

Mitchell, C., et al. (2010). "Long-term follow-up of the United Kingdom medical research council protocols for childhood acute lymphoblastic leukaemia, 1980-2001." Leukemia 24(2): 406-18.

Moe, P. J. and Holen, A. (2000). "HIGH-DOSE METHOTREXATE IN CHILDHOOD ALL." Pediatric Hematology \& Oncology 17(8): 615-622.

Moghrabi, A., et al. (2007). "Results of the Dana-Farber Cancer Institute ALL Consortium Protocol 95-01 for children with acute lymphoblastic leukemia." Blood 109(3): 896904.

Mor, M., et al. (2011). "Invasive fungal infections in pediatric oncology." Pediatr Blood Cancer 56(7): 1092-7.

Moricke, A., et al. (2010). "Long-term results of five consecutive trials in childhood acute lymphoblastic leukemia performed by the ALL-BFM study group from 1981 to 2000." Leukemia 24(2): 265-84.

Moussalem, M., et al. (1995). "Allogeneic bone marrow transplantation for childhood acute lymphoblastic leukemia in second remission: factors predictive of survival, relapse and graft-versus-host disease." Bone Marrow Transplant 15(6): 943-7.

Neale, G. A., et al. (2004). "Comparative analysis of flow cytometry and polymerase chain reaction for the detection of minimal residual disease in childhood acute lymphoblastic leukemia." Leukemia 18(5): 934-8.

Neale, G. A., et al. (1994). "Molecular evidence for minimal residual bone marrow disease in children with 'isolated' extra-medullary relapse of T-cell acute lymphoblastic leukemia." Leukemia 8(5): 768-75.

Oriuchi, N., et al. (2005). "Current status of cancer therapy with radiolabeled monoclonal antibody." Ann Nucl Med 19(5): 355-65.

Ottmann, O. G. and Pfeifer, H. (2009). "Management of Philadelphia chromosome-positive acute lymphoblastic leukemia (Ph+ ALL)." Hematology Am Soc Hematol Educ Program: 371-81.

Patte, C., et al. (2001). "European experience in the treatment of hyperuricemia." Semin Hematol 38(4 Suppl 10): 9-12.

Peng, L. H., et al. (1981). "Fever in children with acute lymphoblastic leukemia." Cancer 47(3): 583-7.

Piccaluga, P. P., et al. (2007). "Tyrosine kinase inhibitors for the treatment of Philadelphia chromosome-positive adult acute lymphoblastic leukemia." Cancer 110(6): 1178-86.

Pinkel, D. (1994). "Role of bone marrow transplantation for acute lymphoid leukemia." J Pediatr 125(3): 506-7.

Porkka, K., et al. (2008). "Dasatinib crosses the blood-brain barrier and is an efficient therapy for central nervous system Philadelphia chromosome-positive leukemia." Blood 112(4): 1005-12. 
Pui, C.-H., et al. (2001). "Recombinant Urate Oxidase for the Prophylaxis or Treatment of Hyperuricemia in Patients With Leukemia or Lymphoma." Journal of Clinical Oncology 19(3): 697-704.

Pui, C. H. (2001). "Urate oxidase in the prophylaxis or treatment of hyperuricemia: the United States experience." Semin Hematol 38(4 Suppl 10): 13-21.

Pui, C. H. (2010). "Recent research advances in childhood acute lymphoblastic leukemia." J Formos Med Assoc 109(11): 777-87.

Pui, C. H. and Campana, D. (2000). "New definition of remission in childhood acute lymphoblastic leukemia." Leukemia 14(5): 783-5.

Pui, C. H., et al. (2009). "Treating childhood acute lymphoblastic leukemia without cranial irradiation." N Engl J Med 360(26): 2730-41.

Pui, C. H., et al. (2010). "Long-term results of St Jude Total Therapy Studies 11, 12, 13A, 13B, and 14 for childhood acute lymphoblastic leukemia." Leukemia 24(2): 371-82.

Pui, C. H., et al. (1997). "Urate oxidase in prevention and treatment of hyperuricemia associated with lymphoid malignancies." Leukemia 11(11): 1813-6.

Pulsipher, M. A., et al. (2011). "High-risk pediatric acute lymphoblastic leukemia: to transplant or not to transplant?" Biol Blood Marrow Transplant 17(1 Suppl): S13748.

Rackoff, W. R., et al. (1996). "Predicting the risk of bacteremia in childen with fever and neutropenia." J Clin Oncol 14(3): 919-24.

Reichert, J. M. and Valge-Archer, V. E. (2007). "Development trends for monoclonal antibody cancer therapeutics." Nat Rev Drug Discov 6(5): 349-56.

Renyi, I., et al. (2007). "Prevention and treatment of hyperuricemia with rasburicase in children with leukemia and non-Hodgkin's lymphoma." Pathol Oncol Res 13(1): 5762.

Riehm, H., et al. (1977). "[The west-berlin therapy study of acute lymphoblastic leukemia in childhood--report after 6 years (author's transl)]." Klin Padiatr 189(8): 89-102.

Riehm, H., et al. (1987). "[Corticosteroid-dependent reduction of leukocyte count in blood as a prognostic factor in acute lymphoblastic leukemia in childhood (therapy study ALL-BFM 83)]." Klin Padiatr 199(3): 151-60.

Rieselbach, R. E., et al. (1964). "Uric Acid Excretion and Renal Function in the Acute Hyperuricemia of Leukemia. Pathogenesis and Therapy of Uric Acid Nephropathy." Am J Med 37: 872-83.

Rosner, F. and Grunwald, H. W. (1973). "Survival in acute lymphocytic leukemia." JAMA 224(10): 1426-7.

Rundles, R. W. (1966). "Effects of allopurinol on 6-mercaptopurine therapy in neoplastic diseases." Ann Rheum Dis 25(6 Suppl): 655-6.

Schotte, D., et al. (2011). "MicroRNA characterize genetic diversity and drug resistance in pediatric acute lymphoblastic leukemia." Haematologica 96(5): 703-11.

Schrappe, M., et al. (2010). "'Educational symposium on long-term results of large prospective clinical trials for childhood acute lymphoblastic leukemia (1985-2000)'." Leukemia 24(2): 253-4. 
Schultz, K. R., et al. (2009). "Improved early event-free survival with imatinib in Philadelphia chromosome-positive acute lymphoblastic leukemia: a children's oncology group study." J Clin Oncol 27(31): 5175-81.

Simone, J. and Pinkel, D. (1973). "Rationale and results of combination chemotherapy and central nervous system irradiation in acute lymphocytic leukemia." Bibl Haematol 39: 1068-73.

Simone, J. V. (1973). "Editorial: Preventive central-nervous-system therapy in acute leukemia." N Engl J Med 289(23): 1248-9.

Simpson, L. D., et al. (1973). "Radiation dosimetry for large, irregularly-shaped fields in the treatment of acute lymphocytic leukemia." Radiology 109(1): 205-7.

Sood, A. R., et al. (2006). "Clarifying the Role of Rasburicase in Tumor Lysis Syndrome." Pharmacotherapy 27(1): 111-121.

Spiegler, B. J., et al. (2006). "Comparison of long-term neurocognitive outcomes in young children with acute lymphoblastic leukemia treated with cranial radiation or highdose or very high-dose intravenous methotrexate." J Clin Oncol 24(24): 3858-64.

Stow, P., et al. (2010). "Clinical significance of low levels of minimal residual disease at the end of remission induction therapy in childhood acute lymphoblastic leukemia." Blood 115(23): 4657-63.

Sung, L., et al. (2004). "Prophylactic granulocyte colony-stimulating factor and granulocytemacrophage colony-stimulating factor decrease febrile neutropenia after chemotherapy in children with cancer: a meta-analysis of randomized controlled trials." J Clin Oncol 22(16): 3350-6.

Topp, M. S., et al. (2011). "Targeted therapy with the T-cell-engaging antibody blinatumomab of chemotherapy-refractory minimal residual disease in B-lineage acute lymphoblastic leukemia patients results in high response rate and prolonged leukemia-free survival." J Clin Oncol 29(18): 2493-8.

Uderzo, C., et al. (1995). "Treatment of childhood acute lymphoblastic leukemia in second remission with allogeneic bone marrow transplantation and chemotherapy: tenyear experience of the Italian Bone Marrow Transplantation Group and the Italian Pediatric Hematology Oncology Association." J Clin Oncol 13(2): 352-8.

van Dongen, J. J., et al. (1999). "Standardized RT-PCR analysis of fusion gene transcripts from chromosome aberrations in acute leukemia for detection of minimal residual disease. Report of the BIOMED-1 Concerted Action: investigation of minimal residual disease in acute leukemia." Leukemia 13(12): 1901-28.

Wang, L. Y., et al. (2006). "Recombinant urate oxidase (rasburicase) for the prevention and treatment of tumor lysis syndrome in patients with hematologic malignancies." Acta Haematol 115(1-2): 35-8.

Watts, R. W. (1966). "Allopurinol in the therapy of neoplasia and blood diseases. Metabolic aspects." Ann Rheum Dis 25(6 Suppl): 657-9.

Wiley, J. M., et al. (1990). "Invasive fungal disease in pediatric acute leukemia patients with fever and neutropenia during induction chemotherapy: a multivariate analysis of risk factors." J Clin Oncol 8(2): 280-6.

Wingard, J. R., et al. (1990). "Allogeneic bone marrow transplantation for patients with highrisk acute lymphoblastic leukemia." J Clin Oncol 8(5): 820-30. 
Wyngaarden, J. B. (1970). "Allopurinol and xanthine nephropathy." N Engl J Med 283(7): 371-2.

Yang, J. J., et al. (2009). "Genome-wide interrogation of germline genetic variation associated with treatment response in childhood acute lymphoblastic leukemia." JAMA 301(4): 393-403.

Young, J. L., Jr. and Miller, R. W. (1975). "Incidence of malignant tumors in U. S. children." Journal of Pediatrics 86(2): 254-8.

$\mathrm{Yu}$, L., et al. (2011). "Microarray detection of multiple recurring submicroscopic chromosomal aberrations in pediatric T-cell acute lymphoblastic leukemia." Leukemia 25(6): 1042-6. 


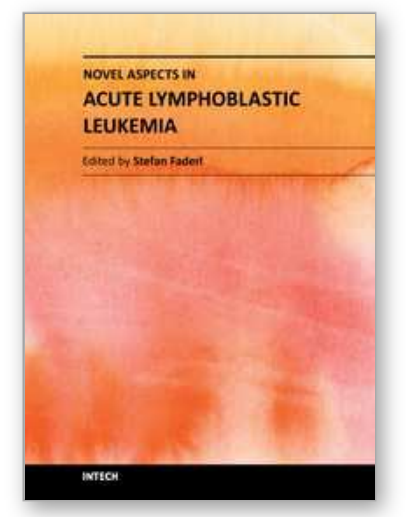

\author{
Novel Aspects in Acute Lymphoblastic Leukemia \\ Edited by Dr. Stefan Faderl
}

ISBN 978-953-307-753-6

Hard cover, 258 pages

Publisher InTech

Published online 16, November, 2011

Published in print edition November, 2011

Acute lymphoblastic leukemia (ALL) has turned from a universally fatal to a highly curable disease in little more than four decades. Even though differences in outcome continue to exist between children and adults, intense efforts are under way to overcome this discrepancy and improve the prognosis of adult patients as well. This exemplary progress in ALL therapy has been possible by the combination of an increasingly better understanding of the biology of the disease, availability of a range of effective drugs, and astute designs and relentless executions of many clinical trials. ALL is a complex disease requiring complex therapy. Whereas this book cannot provide a comprehensive review of every one of its many facets, the chapters from many investigators from around the world nevertheless cover a number of relevant topics: aspects of the epidemiology of ALL in Hispanics, ophthalmologic manifestations of ALL, overviews of current therapy and drug-resistance mechanisms, novel biological pathways and targets, new drugs in development, and long-term consequences of CNS prophylaxis and therapy. The publishers and editor therefore hope that the prospective readers will find enough insight and information for their own endeavors.

\title{
How to reference
}

In order to correctly reference this scholarly work, feel free to copy and paste the following:

Tai-Tsung Chang and Pei-Chin Lin (2011). Treatment of Pediatric Acute Lymphoblastic Leukemia and Recent Advances, Novel Aspects in Acute Lymphoblastic Leukemia, Dr. Stefan Faderl (Ed.), ISBN: 978-953-307-7536, InTech, Available from: http://www.intechopen.com/books/novel-aspects-in-acute-lymphoblasticleukemia/treatment-of-pediatric-acute-lymphoblastic-leukemia-and-recent-advances

\section{INTECH}

open science | open minds

\section{InTech Europe}

University Campus STeP Ri

Slavka Krautzeka 83/A

51000 Rijeka, Croatia

Phone: +385 (51) 770447

Fax: +385 (51) 686166

www.intechopen.com

\section{InTech China}

Unit 405, Office Block, Hotel Equatorial Shanghai

No.65, Yan An Road (West), Shanghai, 200040, China 中国上海市延安西路65号上海国际贵都大饭店办公楼 405 单元

Phone: +86-21-62489820

Fax: $+86-21-62489821$ 
(C) 2011 The Author(s). Licensee IntechOpen. This is an open access article distributed under the terms of the Creative Commons Attribution 3.0 License, which permits unrestricted use, distribution, and reproduction in any medium, provided the original work is properly cited. 